\title{
Influência de Fatores Abióticos na Infestação de Mosca- Negra-dos-Citros (Aleurocanthus woglumi Ashby) em Plantio de Citros em Sistema Agroflorestal no Estado do Pará
}

\author{
Anderson Gonçalves da Silva1 ${ }^{\bowtie}$, Arlindo Leal Boiça Junior¹, Paulo Roberto Silva Farias²,
} Nara Elisa Lobato Rodrigues ${ }^{1}$, Bruno Silva Monteiro ${ }^{3}$ \& Naira Alencar Santos ${ }^{2}$

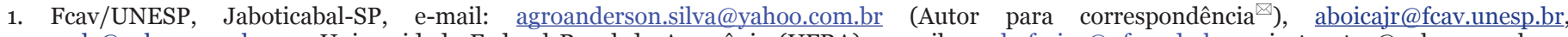
nara elr@yahoo.com.br. 2. Universidade Federal Rural da Amazônia (UFRA), e-mail: paulo.farias@ufra.edu.br, nairotsantos@yahoo.com.br 3. Universidade Federal Rural de Pernambuco (UFRPE), e-mail: brunoufra@yahoo.com.br.

\author{
EntomoBrasilis 4 (1): 01-06 (2011)
}

Resumo. Importante parcela da produção de citros no estado Pará é plantada em Sistema Agroflorestal (SAF), que apresenta, dentre os principais problemas fitossanitários, a mosca-negra-dos-citros que em ataques severos acarretam redução estimada de 80\% na produção. Além de se constitui praga quarentenária presente ou A2 de alerta máximo. Dada a relevância desse inseto sugador e a falta de conhecimentos básicos, bem como estudos da praga associados a plantios agroflorestais, objetivou-se com o presente trabalho avaliar a influência de fatores abióticos na infestação de mosca negra em plantio de citros em sistema agroflorestal no estado do Pará. O presente trabalho foi desenvolvido em área localizada no município de Capitão Poço, mesorregião do Nordeste Paraense. Fez-se 12 amostragens avaliando-se a presença ou ausência de ninfas e/ou adultos vivos de Aleurocanthus woglumi Ashby. Fez-se análise de correlação para avaliar os parâmetros abióticos (temperatura e precipitação) e mapas de Krigagem para avaliar o efeito do sombreamento das plantas de teca na infestação da praga em estudo. Dentre os principais resultados obtidos, verificou-se a infestação da praga em todos os meses avaliados; houve influência da temperatura na regulação da população de mosca-negra-dos-citros e precipitações elevadas reduziram o número de plantas com presença de A. woglumi. Ainda, pode-se inferir que às infestações da mosca-negra-dos-citros apresentam preferência por intensidade moderada de sombreamento, no entanto, as mudanças ocasionadas pela introdução de espécies florestais em cultivos agrícolas, devem ser melhor investigadas.

Palavras-chave: Aleyrodidae; Citrus sinensis; Sombreamento; Tectona grandis

\section{Abiotic Factors Influence on Citrus Blackfly (Aleurocanthus woglumi Ashby) Infestation on Citrus Planting by Agroforestry System at Pará State.}

Abstract. An important part of citrus production at Pará state is planted by Agroforestry System (AFS), that presents, amongst major phytosanitary problems, the citrus blackfly, that by severe attacks cause estimated redution of $80 \%$ in its' production. Beside that, it constitutes a quarentenary pest of maximun alert level A2. Given the relevance of this sucking insect and the lack of basic knowledge, as well pest studies associated to agroforestry planting, the objective of this study was to evaluate the abiotic factors influence on blackfly infestation in citrus planting by agroforestry planting at Pará state. This study was carried out at Capitão Poço county, northeast mesoregion of Pará. 12 samplings were made evaluating the presence or abscence of Aleurocanthus woglumi Ashby alive nymphs and/or adults. Correlation analisys was carried out to evaluate abiotic parameters (temperature and precipitation) and kriging maps to evaluate Teca plants shading effects on the pest under study infestation. Amongst the main results obtained, there was pest infestation in every evaluated moth; there was temperature influence onto citrus blackfly population regulation and high precipitations reduced the number of plants with $A$. woglumi presence. Still, it can be inferred that the citrus blackfly infestations present preference for moderate shading intensity. However, changes occuring by the forestry species introduction onto agricultural cultivations must be better investigated.

Keywords: Aleyrodidae; Citrus sinensis; Shading; Tectona grandis

I mportante para a economia local, a citricultura no estado do Pará atingiu índices elevados de crescimento nos últimos dez anos. Com os avanços nesse período, o Pará passou a assumir posição de destaque, como maior produtor da região norte ficando entre os seis maiores produtores de laranja do Brasil. Apresentando 90\% de sua produção exportada para o estado de São Paulo e para o nordeste brasileiro (IBGE 2009).

Importante parcela da produção de citros (Citrus sinens [L.] Osb.) no estado é plantada em Sistema Agroflorestal (SAF) que são definidos como técnicas alternativas de uso da terra, que implicam na combinação de espécies florestais com culturas agrícolas (YARED et al. 1998). Dentre os principais benefícios da utilização de SAF destacam-se a fixação do homem no campo, diversificação das fontes de renda e otimização do uso da terra, aliado a proteção e melhor estruturação do solo (SANCHES 1995).

Dentre as espécies florestais que são utilizadas consorciadas com citros nesses sistemas, a teca (Tectona grandis Linn. F.) merece destaque por ser espécie arbórea de alto valor comercial (Moreira et al. 2006). Sua madeira é utilizada na produção de peças de usos nobres e de móveis finos e, especialmente, na indústria da construção naval (LAMPRECHT 1990). Encontrando-se em franca expansão nas regiões centrooeste e norte do Brasil, destacando-se os estados do Mato Grosso e Pará (SBS 2009).

Neste sentido a utilização de citros e plantas de teca como componentes de sistemas agroflorestais na Amazônia apresenta um grande potencial, aliada também a uma grande perspectiva de expansão da citricultura na Amazônia, que associada a espécies florestais busca diminuir a pressão sobre a floresta. Contudo, ainda são poucos os estudos sobre eficiência de SAF envolvendo a cultura da laranjeira.

Dentre os principais problemas fitossanitários do 
estado, a mosca-negra-dos-citros, Aleurocanthus woglumi Ashby (Hemiptera: Aleyrodidae) destaca-se por acarretar danos diretos e indiretos ás plantas cítricas, além de se constitui praga quarentenária presente ou A2 de alerta máximo, restringindo o comércio com outras regiões livres da praga (MAPA 2009).

Nativa da Ásia, a mosca-negra-dos-citros apresenta-se amplamente distribuída geograficamente (OliveIra et al. 2001). No Brasil a sua primeira ocorrência foi relatada no estado do Pará, em 16 de maio de 2001, em jardins da cidade de Belém (Silva 2005), e hoje já se encontra disseminada por vários estados brasileiros inclusive no estado de São Paulo, principal produtor de citros, onde teve seu primeiro relato em março de 2008 (PENA et al. 2008).

Na região amazônica a praga encontra condições ideais de desenvolvimento, apresentando ciclo evolutivo bastante rápido (Cunha 2003). Cada fêmea coloca dois a três espirais de ovos durante sua vida, que varia de 10 a 14 dias. Sendo que, em cada postura são colocados de 35 a 50 ovos (Eppo 1997). Sem medidas de controle apropriadas, a praga associada ao fungo fumagina (Capnodium sp.) pode causar perdas sérias a citricultura, com uma redução estimada no rendimento de $80 \%$. Quando o ataque severo se dá nas plantas ainda novas ou em fase de mudas, pode levá-las a morte (PARKINSON \& SEALES 2000).

Os fatores abióticos são importantes para infestação de mosca-negra-dos-citros. CunHA (2003) cita que na região amazônica o A. woglumi encontra condições de umidade e temperatura ótimas de desenvolvimento e que ventos fortes e chuvas pesadas mostraram-se capazes de desalojar e matar adultos da mosca-negra-dos-citros como observado por Flanders (1969) em trabalho no México. Já fatores associados a introdução de espécies florestais consorciadas com cultivos agrícolas influenciam na atividade de insetos devido a mudanças no microclima ocasionadas pelo sombreamento proporcionado, também por atuarem como barreiras a disseminação de artrópodes pela cultura, como já observado em estudos de RATHORE \& FELLOW (1995) e RAO et al. (2000).

Dessa forma, por ser uma praga exótica, recém introduzida, faltam conhecimentos básicos para a implementação de um manejo adequado do $A$. woglumi na região amazônica. Dada a relevância desse inseto sugador e a falta de conhecimentos básicos, bem como estudos da praga associados a plantios agroflorestais, objetivou-se com o presente trabalho avaliar a influência de fatores abióticos na infestação natural de moscanegra-dos-citros em plantio de citros em sistema agroflorestal no estado do Pará.

\section{MATERIAL E MÉTODOS}

O presente trabalho foi desenvolvido de setembro de 2008 a agosto de 2009. A área experimental está localizada no município de Capitão Poço, mesorregião do Nordeste Paraense, microrregião do Guamá, distante 200 km de Belém, PA. A Fazenda Santana está compreendida nas coordenadas geográficas: $01^{\circ} 45^{\prime}$ 15 ” de latitude Sul, $47^{\circ}$ 07' 30" de longitude Oeste de Greenwich (sede da fazenda), apresentando solo do tipo Latossolo Amarelo Álico, textura média, clima tipo Ami, segundo a classificação de Köppen, apresentando os maiores índices de pluviosidade de janeiro a maio e os menores de agosto a novembro.

A área experimental constituída pelo sistema agroflorestal (Figura 1) é constituída por um pomar de laranjeiras da variedade "Pêra Rio" (C. sinensis), enxertadas em limão cravo (Citrus limonia Osbeck), plantadas em espaçamento de $5 \times 7 \mathrm{~m}$, apresentando sete anos de idade; distribuídas em 32 fileiras, com 52 plantas de citros por linha de plantio. Possuindo 1.664 plantas, totalizando $58.240 \mathrm{Om}^{2}$, o que corresponde a $89,9 \%$ da área total do sistema agroflorestal. Apresentando densidade de plantio de 285 laranjeiras por hectare.

Na área, a distribuição das plantas de teca se da a cada três linhas de plantio de citros totalizando 11 linhas com plantas de teca (Figura 1). Essas estão distribuídas na linha de plantio a cada três plantas de citros, totalizando 187 plantas de teca correspondendo a 10,1\% da área total do sistema agroflorestal (Figura 2).

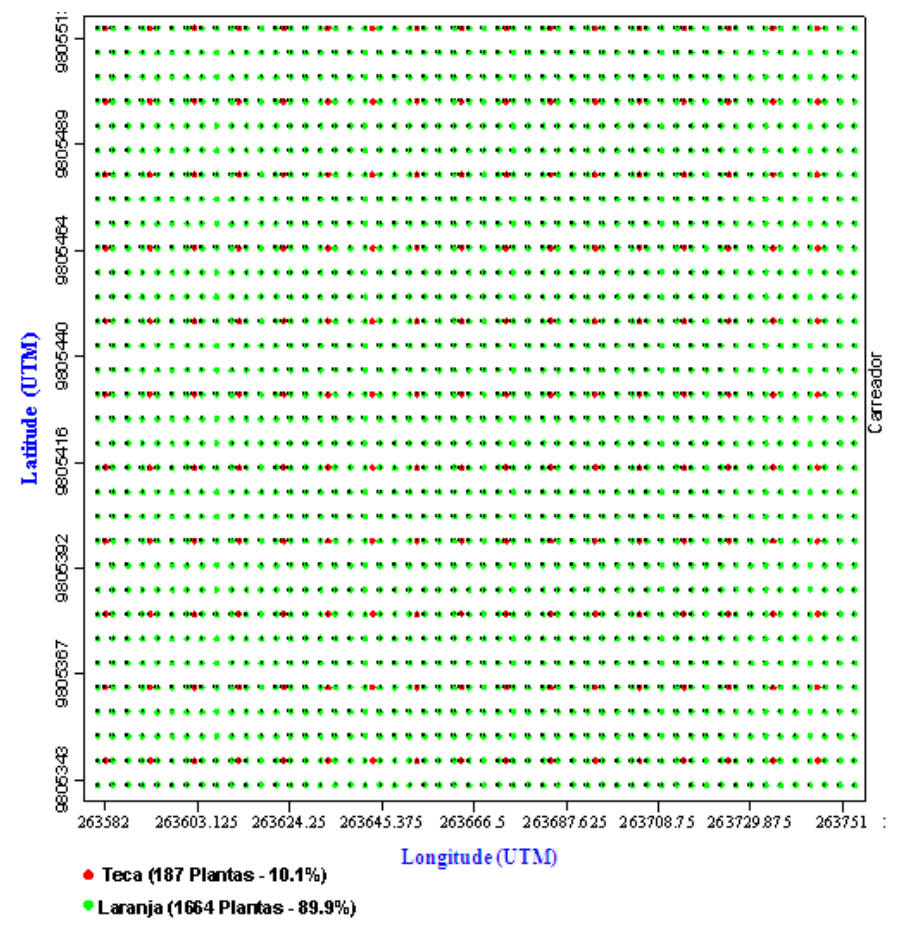

Figura 1. Croqui da área experimental mostrando a área de plantio no sistema agroflorestal. Fazenda Santana, Capitão Poço - PA, 2008/2009.

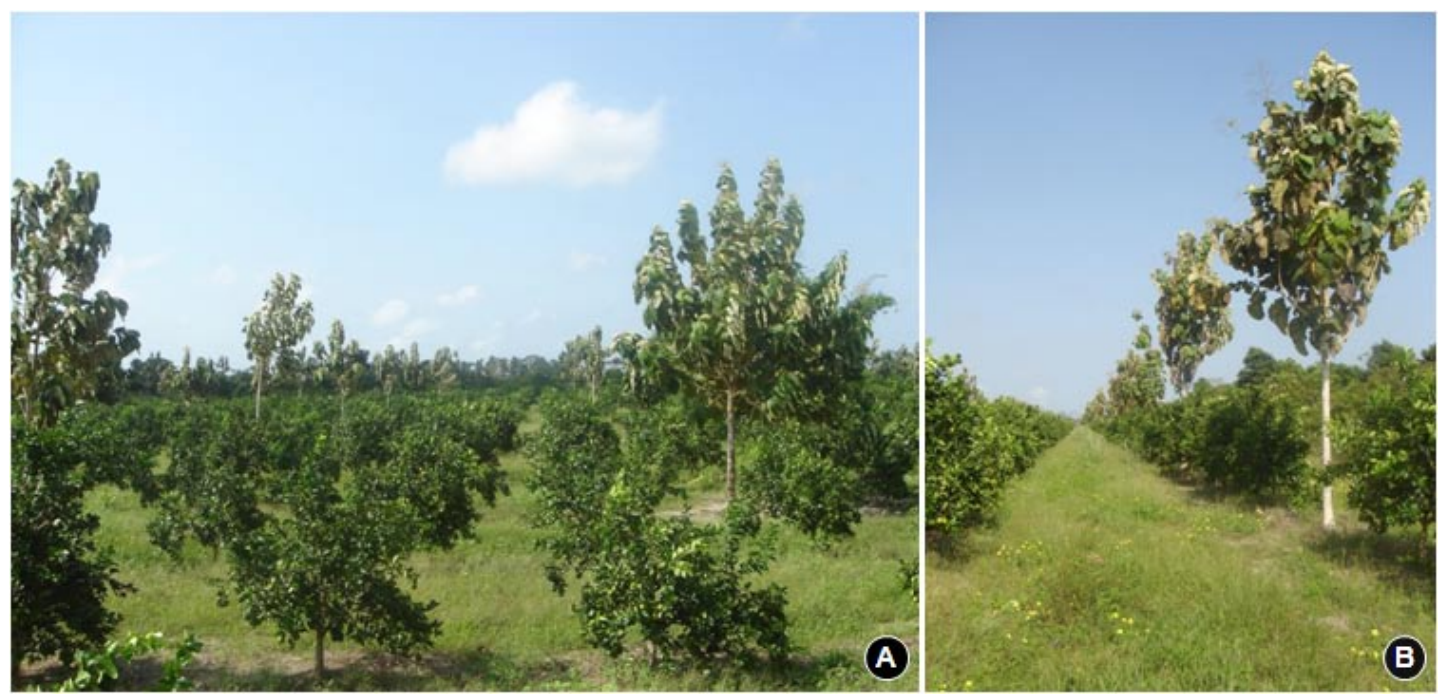

Figura 2. Visualização do sistema de plantio agroflorestal com laranja (C. sinensis) e teca (T. grandis). (A) na entrelinha e (B) na linha de plantio. Fazenda Santana, Capitão Poço - PA, 2008/2009. 
Á área experimental recebeu adubação de acordo com análise de solos, considerando ás exigências nutricionais da cultura dos citros. Quanto ao controle de plantas daninhas, esse foi feito através de roçadeira mecânica nas ruas do pomar e com uso de herbicida nas linhas de plantio. $\mathrm{Na}$ área experimental não se utilizou inseticida no período das avaliações de $A$. woglumi.

Olevantamento populacional demosca-negra-dos-citros foi realizado em $100 \%$ das laranjeiras nos sistemas de plantio agroflorestal (avaliação em varredura), avaliando-se a presença ou ausência de ninfas e/ou adultos vivos de A. woglumi (Figura 3). Todas as plantas foram vistoriadas, observando principalmente brotações novas (onde geralmente são encontrados os adultos) e também a parte abaxial das folhas onde se encontram todas as fases imaturas da praga, anotando-se presença da praga com o número um (1) ou ausência da mesma com o número zero (o), para o presente sistema de produção. Realizou-se 12 amostragens, essas nas seguintes datas: 18/09/08; 20/10/08; 17/11/o8; 13/12/o8; 17/01/09; 06/02/09; 25/03/09; 22/04/o9; 19/05/09; 26/06/09; 24/07/09 e 16/08/09.

Os dados climáticos médios mensais como precipitação pluviométrica $(\mathrm{mm})$ e temperatura $\left({ }^{\circ} \mathrm{C}\right)$ para o município de Capitão Poço - PA, foram obtidos junto à estação meteorológica da empresa Cítricos do Pará - CITROPAR (Estação meteorológica situada próximo ao local do presente experimento) e apresentamse, juntamente com o índice de plantas com presença de $A$. woglumi (\%) na Tabela 1.

Tabela 1. Infestação e variáveis climáticas de mosca-negra-dos-citros (A. woglumi) em plantio de citros em sistema agroflorestal. Fazenda Santana, Capitão Poço - PA, 2008/2009.

\begin{tabular}{|c|c|c|c|c|c|}
\hline \multirow{2}{*}{$\begin{array}{c}\text { Datas de } \\
\text { Amostragem }\end{array}$} & \multirow{2}{*}{$\begin{array}{c}A . \\
\text { woglumi } \\
\text { (\%) }\end{array}$} & \multicolumn{3}{|c|}{ Temperatura (oC) } & \multirow{2}{*}{$\begin{array}{l}\text { Precipitacão } \\
\text { média mensal } \\
\text { (mm) }\end{array}$} \\
\hline & & Mínima & Média & Máxima & \\
\hline Setembro/2008 & 37 & 22,3 & 28,0 & 33,6 & 26 \\
\hline Outubro/2008 & 51 & 22,2 & 28,1 & 34 & 51 \\
\hline Novembro/2008 & 53 & 22,4 & 28,4 & 34,3 & 46 \\
\hline Dezembro/2008 & 25 & 22,1 & 27,8 & 33,5 & 78 \\
\hline Janeiro/2009 & 50 & 21,5 & 27,8 & 34 & 228 \\
\hline Fevereiro/2009 & 6 & 22,7 & 26,7 & 30,6 & 348 \\
\hline Março/2009 & 12 & 23 & 26,8 & 30,6 & 447 \\
\hline Abril/2009 & 39 & 22,9 & 26,6 & 30,2 & 75 \\
\hline Maio/2009 & 46 & 22,5 & 26,5 & 30,5 & 65 \\
\hline Junho/2009 & 25 & 21,5 & 26,5 & 31,5 & 45 \\
\hline Julho/2009 & 13 & 20,8 & 26,4 & 32 & 37 \\
\hline Agosto/2009 & 27 & 20,8 & 26,8 & 32,8 & 39 \\
\hline
\end{tabular}

Determinou-se as correlações, objetivando analisar o índice de plantas com presença de mosca negra com as variáveis precipitação pluviométrica $(\mathrm{mm})$ e temperatura média $\left({ }^{\circ} \mathrm{C}\right)$. Para todas as análises utilizou-se o programa computacional
STATISTICA 7.0 ® (STATSOFT 2004).

Os procedimentos geoestatísticos utilizados para confecção dos mapas de Krigagem para os diâmetros (DAP) de plantas de teca ( $T$. grandis) e infestação de A. wogumi na área experimental durante as avaliações, seguem a metodologia de VIEIRA et al. (1983).

\section{RESULTADOS E DISCUSSÃO}

Para os resultados obtidos, observou-se a incidência de mosca-negra-dos-citros em todas as avaliações, com infestação variando de 6 a 53\%. Outubro, novembro e janeiro foram os meses que apresentaram maior índice de plantas com presença da praga com respectivamente 51; 53 e 50\%. Fevereiro, março e julho foram os meses que apresentaram resultados inferiores com respectivos 6; 12 e 13\% (Figura 4).

MaIA (2008) em estudos em plantio de citros em monocultivo, na mesma região do presente trabalho, observou que a densidade populacional de $A$. woglumi foi maior nos meses de dezembro, janeiro, fevereiro e outubro com média de $90 \%$ da área experimental infestada, apresentando-se menor nos meses de abril, maio, junho e julho com média de $25 \%$ de infestação para os referidos meses citados. Infestações essas maiores que as encontradas no presente trabalho. De acordo com Murdoch et al. (1972) e BACH et al. (1982), é de se esperar que com o aumento da diversidade de plantas, ocorra uma diminuição da herbivoria por parte de pragas, devido a uma maior estabilidade proporcionada pelos sistemas mais complexos como os agroflorestais quando comparados com plantios convencionais.

Avaliou-se a influencia dos fatores abióticos na infestação natural de mosca-negra-dos-citros, pois diversos trabalhos corroboram que as condições climáticas, dentre elas a precipitação e temperatura podem influenciar na infestação de insetos fitófagos (TRNKAA et al. 2007; BATALDEN et al. 2007).

A Tabela 2 mostra correlação positiva entre temperatura média e índice de plantas infestadas $\left(\mathrm{r}=0,6077^{*}\right)$, valor esse significativo a $5 \%$ de probabilidade. Para o presente trabalho a temperatura mostrou-se elevada durante todas as avaliações, condições essas características da região amazônica e tidas como ideais para o desenvolvimento da mosca-negra-dos-citros (SiLvA 2005), nessas condições a mosca negra apresenta ciclo evolutivo bastante rápido, chegando a apresentar de 5 a 6 gerações anuais (CunHA 2003); apresentando sobreposição de gerações, ou seja, em todas as avaliações eram observados os estágios de ovo, ninfa e adulto de A. woglumi (Silva 2005).

Quanto à precipitação pluviométrica, esta apresentou correlações não significativas (Tabela 2). No entanto precipitações elevadas reduziram a infestação da mosca negra como se pode observar na Figura 4.

A influência da precipitação no número de plantas com presença de $A$. woglumi foi bem nítida nos meses mais chuvosos, principalmente fevereiro e março (348, 447mm respectivamente) (Tabela 1), com redução drástica da praga na área experimental,
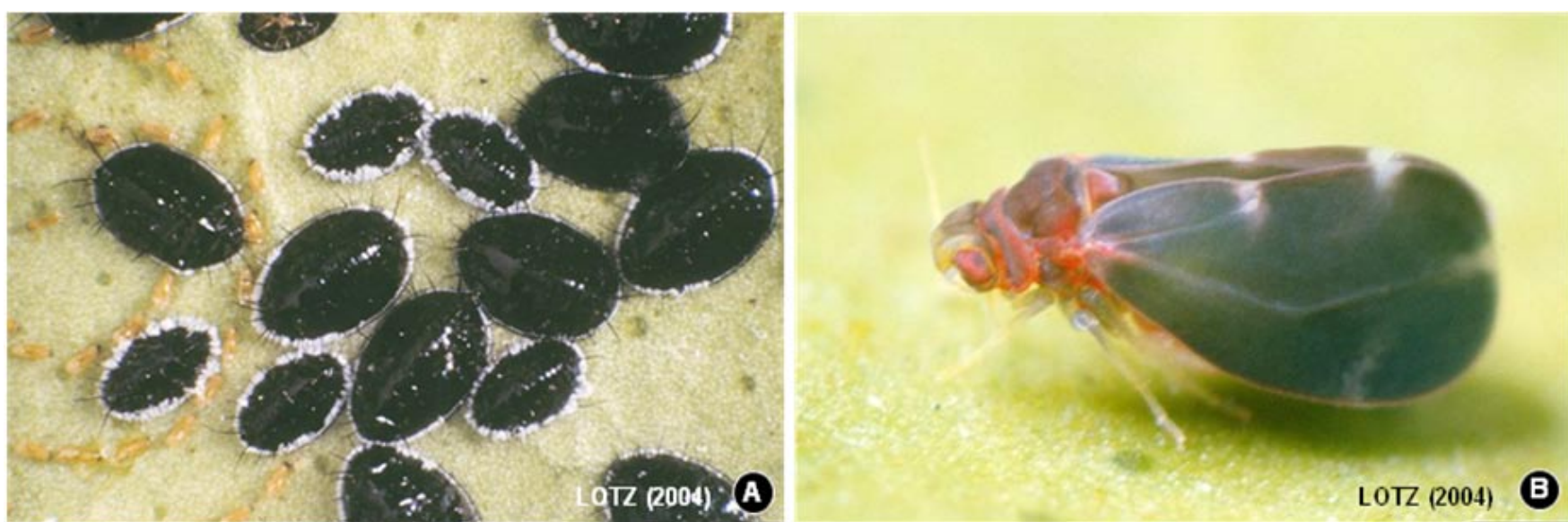

Figura 3. Estágios de Mosca-negra-dos-citros (Aleurocanthus woglumi), levados em consideração para a realização das amostragens: (A) ninfas e (B) adulto. 
apresentando 6 e $12 \%$ de plantas com presença da praga nos referidos meses.

Tabela 2. Coeficientes de correlação linear simples (r) entre o índice de plantas com presença de mosca-negra-dos-citros (A. woglumi) e temperatura mínima, média e máxima mensal $\left({ }^{\circ} \mathrm{C}\right)$ e precipitação pluviométrica mensal $(\mathrm{mm})$ em plantio de citros em sistema agroflorestal. Fazenda Santana, Capitão Poço - PA, 2008/2009

\begin{tabular}{|c|c|}
\hline \multirow[t]{2}{*}{ Correlação } & $\begin{array}{l}\text { Coeficientes de } \\
\text { Correlação (r) } \\
\end{array}$ \\
\hline & Sistema Agroflorestal \\
\hline $\begin{array}{l}\text { Infestação de } A \text {. woglumi x Temp. } \\
\text { Mínima }\end{array}$ & $0.084^{\mathrm{ns}}$ \\
\hline Infestação de A. woglumi x Temp. Média & $0.6077^{*}$ \\
\hline $\begin{array}{l}\text { Infestação de } A \text {. woglumi x Temp. } \\
\text { Máxima }\end{array}$ & $0.5282^{\text {ns }}$ \\
\hline Infestação de A. woglumi x Precipitação & $0.4813^{\text {ns }}$ \\
\hline
\end{tabular}

FLANDERS (1969), em trabalho realizado no México, observou que ventos fortes e chuvas pesadas mostraram-se capazes de desalojar e matar adultos da mosca-negra-doscitros. Mesmo resultado encontrado por MEdeIRos et al. (2009), estudando em condições de campo a dinâmica populacional da mosca-negra-dos-citros em Citrus spp. no município de São Luís - MA, observaram que no período chuvoso houve redução no número de posturas, ovos, e ninfas nas áreas experimentais. MAIA (2008), estudando a distribuição da mosca-negra-dos-citros a fim de determinar um plano de amostragem sequencial observou que a diminuição da população está relacionada ao fato de que chuvas intensas podem ser fatores importantes de mortalidade de adultos, além da alta proliferação de microorganismos que favorece o controle microbiano desse inseto.

Para os meses de abril e maio observou-se índice elevado de plantas com presença de mosca negra, logo após um período intenso de chuvas (janeiro, fevereiro e março) (Figura 4), esse aumento de plantas infestadas está relacionado a um maior crescimento vegetativo das plantas de citros que se da nesse período de maior precipitação na Região Norte do país, e por essa fase ser a preferida para alimentação e oviposição de $A$. woglumi.

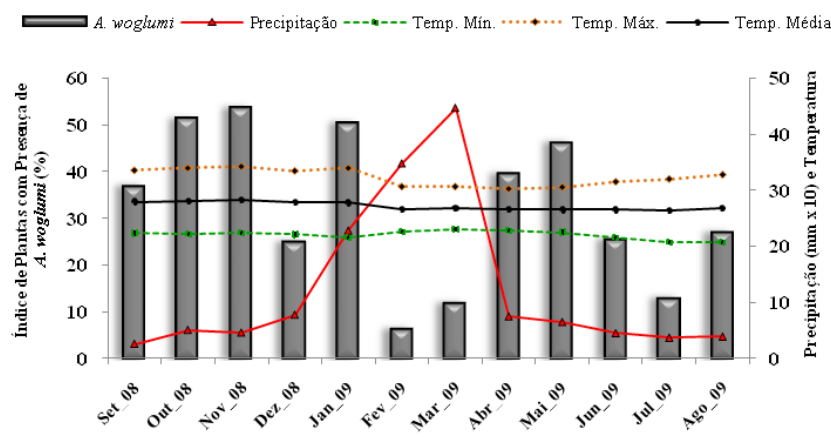

Figura 4. Índice de plantas com presença de mosca-negra-dos-citros (A. woglumi), precipitação pluviométrica acumulada $(\mathrm{mm} \times 10)$ e temperaturas mínima, média e máxima $\left({ }^{\circ} \mathrm{C}\right)$ em sistema agroflorestal de citros. Fazenda Santana, Capitão Poço - PA, 2008/2009.

O diâmetro altura do peito (DAP) das plantas de teca componentes do sistema de plantio agroflorestal está diretamente ligado com o tamanho da copa. Portanto espera-se que quanto maior o DAP maior a copa das plantas de teca, logo um maior sombreamento proporcionado, bem como maior efeito de barreira na disseminação da praga na área experimental. Neste sentido a Figura 5 representa, através de mapas de Krigagem, a distribuição dos diâmetros de plantas de teca na área experimental. Tons de verde mais escuro representam plantas com maiores diâmetros, tons claros diâmetros menores e em vermelho temos a localização das plantas de citros que apresentavam presença da moscanegra-dos-citros nos respectivos meses amostrados.
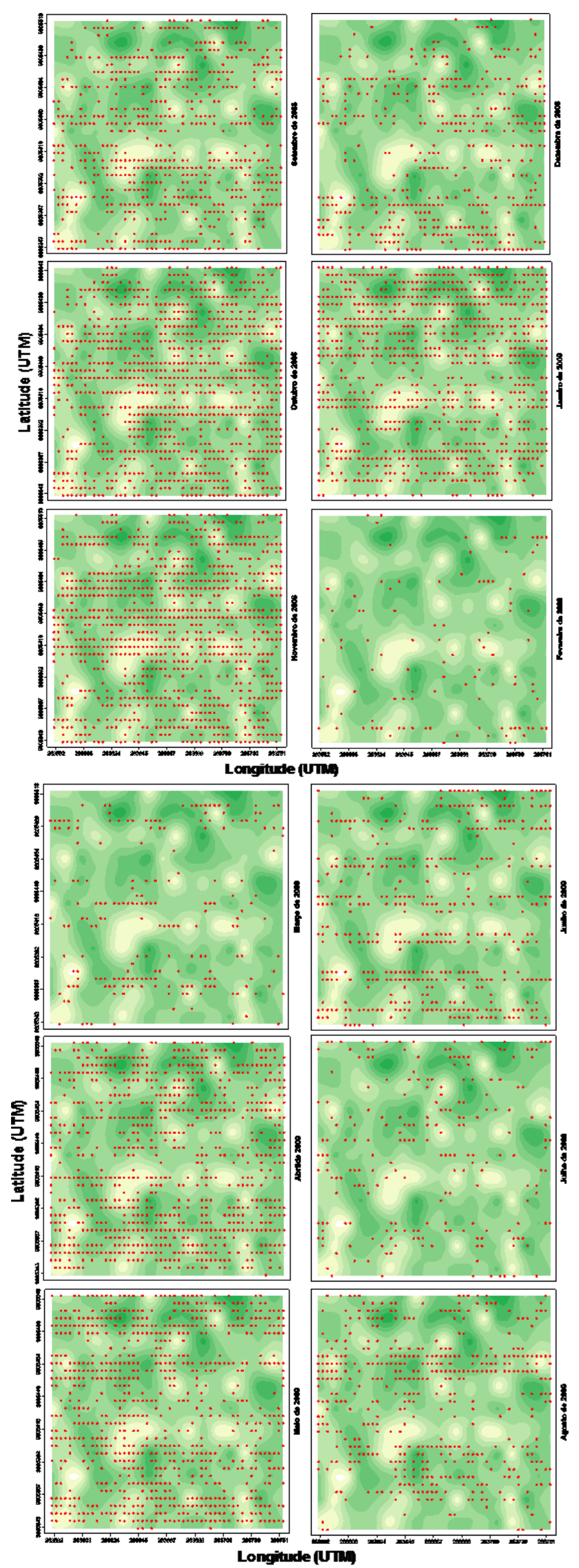

Figura 5. Mapas de Krigagem para os diâmetros (DAP) de plantas de teca (T. grandis) em sistema de plantio agroflorestal. Fazenda Santana. Capitão-Poço - PA, 2008/ 2009. 
Observou-se na área que em períodos de alta infestação não é possível estabelecer um padrão ou preferência de sombreamento para infestação de mosca-negra-dos-citros. Este pode ser visto nos meses de setembro, outubro, novembro, janeiro, abril e maio; onde o índice de plantas com presença da mosca-negra-dos-citros apresentava-se em torno de 50\%.

Já para os meses de menor índice de plantas com presença da praga, com destaque para os meses de fevereiro e março, período em que o índice de plantas com presença de $A$. woglumi encontrava-se bastante reduzido nas áreas experimentais; observa-se que praticamente não há presença da praga nas áreas (manchas) de verde mais intenso onde se encontram as plantas de teca que apresentam os maiores diâmetros (DAP), consequentemente maiores projeções de copa o que propiciou um maior sombreamento.

O mesmo padrão é visto também nas áreas de cores mais claras que representam um diâmetro (DAP) reduzido, e até mesmo ausência de plantas de teca aja visto que foram observadas algumas falhas de plantio e mesmo plantas de teca mortas na área, justificando a ausência de sombreamento nessas referidas áreas.

Desse modo pode-se inferir através da visualização dos mapas que às infestações da mosca-negra-dos-citros apresentam preferência por intensidade moderada de sombreamento nos períodos de menor infestação da praga no sistema de plantio agroflorestal.

RAO et al. (2000), em estudo envolvendo sistemas agroflorestais observaram que o sombreamento proporcionado pela cultura de sub-bosque (no presente estudo ás plantas de teca), favorece a redução da temperatura do ar e do solo e a manutenção ou aumento do teor de umidade, como também a diminuição da velocidade do vento, sendo que estas alterações podem trazer impactos positivos ou negativos sobre a atividade dos insetos e seus inimigos naturais como parasitóides, predadores e microorganismos entomopatogênicos, mas é de se esperar que a atividade dos insetos sejam maiores em ambientes sombreados.

Comportamento semelhante foi observado por Doube (1983) que constatou que a maioria dos insetos diurnos apresenta preferência para alimentação em áreas sombreadas, evitando a exposição direta ao sol e que em condições normais de sombreamento sua atividade alimentar pode ser aumentada, aumentando também o seu potencial de dano, fato também relatado para a maioria das espécies de afídeos, que preferem condições de sombreamento, de acordo com estudos de RATHORE \& Fellow (1995). Que acrescentam que quando cultivados juntos, espécies florestais e plantios agrícolas, ocorrem mudanças no microclima influenciando na atividade dos insetos dentro do sistema.

Esses mesmos autores afirmam que plantas utilizadas no sistema agroflorestal podem atuar como barreiras físicas ao movimento dos insetos dentro do sistema. Um efeito de barreira pode também resultar da presença de plantas não-hospedeiras entre as plantas hospedeiras, fato corroborado por RAO et al. (2000). Estes autores afirmaram que as espécies florestais afetam também infestações justamente por agirem como uma barreira ao movimento dos insetos.

Dentre os principais resultados obtidos, verificouse a infestação da praga em todos os meses avaliados; houve influência da temperatura na regulação da população de moscanegra-dos-citros e precipitações elevadas reduziram o número de plantas com presença de A. woglumi. Ainda, pode-se inferir que às infestações da mosca-negra-dos-citros apresentam preferência por intensidade moderada de sombreamento nos períodos de menor infestação da praga. No entanto as mudanças ocasionadas pela introdução de espécies florestais em cultivos agrícolas devem ser melhor investigadas.

\section{AGRADECIMENTOS}

Ao Conselho Nacional de Ciência e Tecnologia - CNPq pela bolsa de mestrado concedida ao primeiro autor. A Fazenda Santana, Capitão Poço - PA, por disponibilizar a área para o desenvolvimento do experimento do presente trabalho.

\section{REFERÊNCIAS}

Bach, C.E., J.H. Vandermeer, K.H. Boucher \& D. De Steven, 1982. Variation in insect community structure in a tropical secondary habitat. Brenesia, 20: 171 - 179.

Batalden, R.V., K. Oberhauser \& A.T. Peterson, 2007. Ecological niches in sequential generations of eastern North American Monarch Butterflies (Lepidoptera: Danaidae): The Ecology of Migration and Likely Climate Change Implications. Environmental Entomology, 36: 1365 - 1373 .

Cunha, M.L.A., 2003. Distribuição, hospedeiros, densidade populacional, aspectos biológicos e controle químico da mosca negra dos citros (Aleurocanthus woglumi Ashby) nas condições do Estado do Pará. 54f. Dissertação (Mestrado em Agronomia) - Universidade Federal Rural da Amazônia, Belém.

Doube, B.M., 1983. The habitat preference of some bovine dung beetles (Coleoptera: Scarabaeidae) in Hluhluwe Game Reserve, South Africa. Bulletin of Entomological Research, 73: $357-371$.

Eppo, 1997. European and mediterranean plant protection organization. Aleurocanthus woglumi. In: Quarantine Pests for Europe, 2. ed, Wallingford: $\mathrm{CAB}$ International, 25 - 29.

Flanders, S.E., 1969. Observations on citrus blackfly parasites in índia and México and correlated circunstances. Canadian Entomologist, 101: $467-480$.

Ibge, 2009. Instituto Brasileiro de Geografia e Estatística. Estados, lavoura permanente. Disponível.em: <http://www. ibge.gov.br/estadosat/temas.php?sigla=pa\&tema=lavourape rmanente2009>. Acesso em: 17 out. 2009.

Lamprecht, H., 1990. Silvicultura nos trópicos: ecossistemas florestais e respectivas espécies arbóreas- possibilidades e métodos de povoamento sustentado. Eschborn: Instituto de Silvicultura da Universidade de Göttingen, 310 - 313.

Maia, P.S.P., 2008. Caracterização da distribuição espacial da mosca negra dos citros (Aleurocanthus woglumi Ashby, 1915) em pomar georreferenciado para determinar um plano de amostragem seqüencial. 77f. Dissertação (Mestrado); Universidade Federal Rural da Amazônia, Belém.

Mapa, 2009. Ministério da Agricultura, Pecuária e Abastecimento. Lista de pragas quarentenárias presentes - (A2). Disponível em: <http://extranet.agricultura.gov.br/sislegisconsulta/ servlet/VisualizarAnexo?id=14644>. Acesso em: $23 \mathrm{dez}$. 2009.

Medeiros, F.R., R.N.S. Lemos, A.L.T. Ottati, J.R.G. Araújo, K.K.G. Machado \& A.A.C. Rodrigues, 2009. Dinâmica populacional da mosca-negra-dos-citros Aleurocanthus woglumi ashby (Hemiptera: Aleyrodidae) em Citrus spp. no município de São Luís - MA. Revista Brasileira de Fruticultura, 31: 1016 - 1021.

Moreira, R.Y.O., M.S.P. Arruda, A.C. Arruda, L.S. Santos, A.H. Müller, M.S.P. Giulhon, A.S. Santos \& E. Terezo, 2006. Antraquinonas e naftoquinonas do caule de um espécime de reflorestamento de Tectona grandis (Verbenaceae). Revista Brasileira de Farmacognosia, 16: 392-396.

Murdoch, W.W., F.C., Evans \& C.H. Peterson, 1972. Diversity and pattern in plants and insects. Ecology, 53: 819 - 829.

Oliveira, M.R.V., C.C.A., Silva \& D. Navia, 2001. Mosca negra dos citros Aleurocanthus woglumi: alerta quarentenário. Brasília: Ministério da Agricultura, Pecuária e Abastecimento, 12p.

Parkinson, K. \& J. Seales, 2000. Citrus blackfly, its presence and management in Trinidad and Tobago. Procaribe News, Network, 11p.

Pena, M.R., J.D. Vendramim, A.L. Lourenção, N.M. Silva, P.T. Yamamoto \& M.S. Gonçalves, 2008. Ocorrência da moscanegra-dos-citros, Aleurocanthus woglumi Ashby (Hemiptera: Aleyrodidae) no estado de São Paulo. Revista Brasileira de 
Engenharia Agrícola e Ambiental, 83: 61 - 65.

Rao, M., M. Singh \& R. Day, 2000. Insect pest problems in tropical agroforestry systems: Contributory factors and strategies for management. Springer, 50: 243 - 277.

Rathore, M. P. \& S.V. Fellow, 1995. Insect pests in agroforestry. (Working Paper, 70). GTZ.

Sanches, P., 1995. Science in agroforestry. Agroforestry Systens, 30: $05-55$.

Sbs. Sociedade Brasileira de silvicultura. Fatos e números do Brasil florestal. 2009.

Silva, A.B., 2005. Mosca negra dos citros, Aleurocanthus woglumi Ashby, praga potencial para a citricultura brasileira. In: Poltronieri, L.S., D.R. Trindade \& I.P. Santos. Pragas e doenças de cultivos amazônicos. Belém: Embrapa Amazônia Ocidental, 147 - 156.

Statsoft, 2004. Statistica: data analysis software system. Version 7.o. Disponível em: <http://www.statsoft.com $>$. Acesso em: 18 jul. 2009.

\section{Como citar este artigo:}

A.G. Silva, A.L. Boiça Junior, P.R.S. Farias, N.E.L.Rodrigues, B.S.Monteiro \& N.A.Santos, 2011. Influência de Fatores Abióticos na Infestação de Mosca-Negra-dos-Citros (Aleurocanthus woglumi Ashby) em Plantio de Citros em Sistema Agroflorestal no Estado do Pará. EntomoBrasilis, 4 (1): 01-06. www.periodico.ebras.bio.br/ojs
Trnkaa, M., F. Mus`kab, D. Semerádová, C.M. Dubrovský, E. Kocmánková \& Z. Alud, 2007. European corn borer life stage model: Regional estimates of pest development and spatial distribution under present and future climate. Ecological Modelling, 207: 61 - 84 .

Vieira, S.R., T.L. Hatfield, D.R. Nielsen \& J.W. Biggar, 1983. Geostatistical theory and application to variability of some agronomical properties. Hilgardia, 51:1-75.

Yared, J.A.G., S. Brienza Júnior \& L.C.T. Marques, 1998. Agrossilvicultura: conceitos, classificação e oportunidades para a aplicação na Amazônia brasileira. Belém: EmbrapaCPATU, (Embrapa-CPATU. Documento, 104), 39p.

Recebido em: 25/10/2010

Aceito em: 23/12/2010

$* * * * * * * * * * * * *$

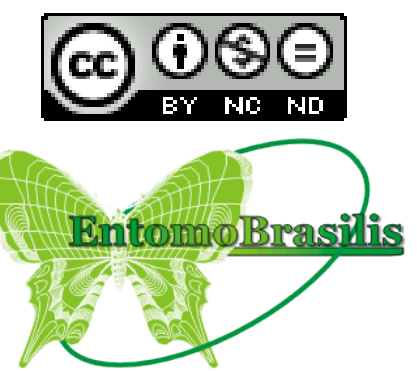

